\title{
0 \\ AIAA 2002-2743 \\ Boundary Layer Transition On Slender Cones In Conventional And Low Disturbance Mach 6 Wind Tunnels
}

Thomas J. Horvath, Scott A. Berry, Brian R. Hollis, Chau-Lyan Chang, and Bart A. Singer

NASA Langley Research Center

Hampton, VA 23681-2199

\section{2nd AIAA Fluid Dynamics Conference and Exhibit \\ June 24-27, 2002 St. Louis, Missouri}




\title{
BOUNDARY LAYER TRANSITION ON SLENDER CONES IN CONVENTIONAL AND LOW DISTURBANCE MACH 6 WIND TUNNELS
}

\author{
Thomas J. Horvath*, Scott A. Berry*, Brian R. Hollis:" \\ Chau-Lyan Chang ${ }^{+}$, and Bart A. Singer ${ }^{\dagger}$. \\ NASA Langley Research Center
}

\begin{abstract}
An experimental investigation was conducted on a 5-degree half-angle cone and a 5-degree half-angle flared cone in a conventional Mach 6 wind tunnel to examine the effects of facility noise on boundary laver transition. The influence of tunnel noise was inferred by comparing transition onset locations determined from the present test to that previously obtained in a Mach 6 low disturbance quiet tumnel. Together, the two sets of experiments ate believed to represent the first direct comparison of transition onset between a conventional and a low distarbane wind tunnel asing a common test model and transition dotection technique. In the present comventional hypersonic tumnel experiment, separate measurements of heal transfer and adiabatic wall temperatures were obtained on the conical models at small angles of attack over a range of Revnolds numbers, which resulted in laminar, transitional. and turbulent flow. Smooth model turbulent heating distributions are compared to that obtained with transition forced via discrete surface roughness. The model nosetip radius was varied to examine the effects of blunthess on transition onset. Despite wall-to-total temperature differences between the transient heating measurements and the adiabatic wall temperature measurements, the two methods for determining sharp cone transition onset generally vielded equivalent locations. In the "noisy" mode of the hypersonic low disturbance tunnel, transirion onset octured earlier than that measured in the conventional hypersonic tunnel, suggesting higher lovels of frecestream acoustic radiation relative to the conventional tannel. At comparable freestream conditions, the transition onset Revnolds number under low disturbance conditions was a factor of 1.3 greater than that measured on flared cone in the LaRC conventional hypersonic tumnel and a factor of 1.6 greater than the flared cone run in the low disturbance funnel run "noisy". Navier-Stokes mean flow compuations and linear stability analysis were conducted to assess the experimental results and have indicated $N$ factors associated with sharp flared cone transition onsel to be approximately a factor of 2 lower than that inferred from the corresponding low disturbance annel measurements.
\end{abstract}

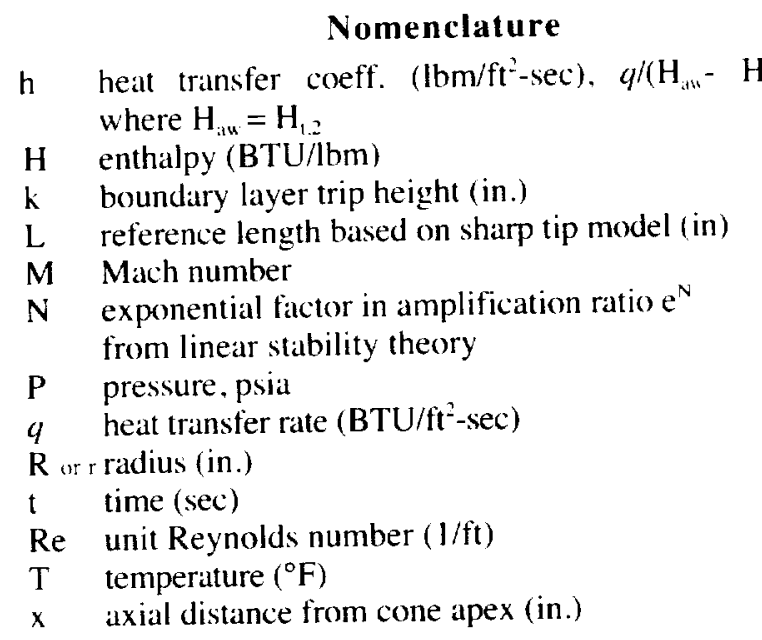

\footnotetext{
*Aerothermodynamies Branch, NASA Langley Research Center. Hamplon. VA

$†$ Computational, Modeling \& Simulation Branch. NASA Langley Research Center, Hampton, VA.

+ Member. AlA

Copyright 02002 by the American Institute of Acronatucs and

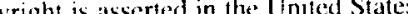
Astronatics. Inc. No copyrighe U.S. Government has a royalty-lree under Tille 17, U.S. Code. The U.S. Government has at royaly-free license to exercise all rights under the copyright elaimed herein for
government purposes. All other rights are reserved by the copyright owner
}

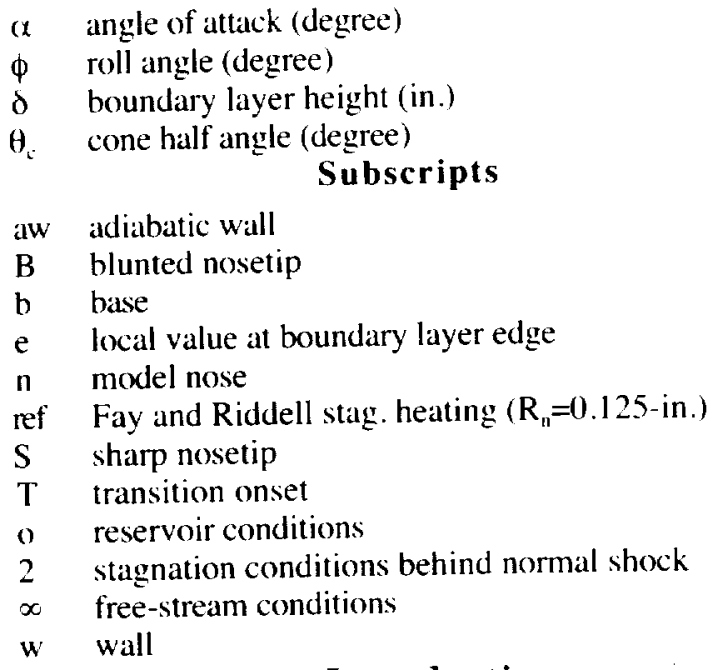

\section{Introduction}

Thermal effects resulting from boundary layer transition during hypersonic ascent, cruise, or entry can represent an important thermal protection system (TPS) design constraint ${ }^{\prime}$. From a thermal protection perspective, the success of the ceramic-based tiles utilized on the US shuttle orbiter was in some regards the consequence of a conservative (and costly) design philosophy. Strategies for achieving an economically viable next generation space transportation system with 
testing will continue into the near future. Most of the NASA's recently proposed $X$-vehicles have been tested in the NASA LaRC 20-Inch Mach 6 Air Tunnel with a majority of the aerothermodynamic studies emphasizing hypersonic transition and the characterization of surface roughness effects ${ }^{33-\alpha_{1}}$. While it is recognized that improvements in TPS technology have been made since the first flight of the US shuttle orbiter, most have not been flight demonstrated. A recent review of roughnessdominated transition suggests TPS technology for reentry vehicles in the near future may continue to be roughness dominated ${ }^{57}$. Traditional ceramic TPS tiles such as those used on the Shuttle Orbiter often suffer launch-induced damage and/or develop protruding gap fillers. Both forms of local surface roughness have been responsible for the occurrence of early boundary layer transition in flight ${ }^{5 x}$. Stitching patterns found on thermal blankets produce another form of local roughness. Metallic TPS panels that were proposed for use on the $X-33^{3.54-(x)}$ could have been susceptible to thermally induced expansion/bowing producing roughness in the form of a wavy wall.

It is generally accepted that boundary layer transition can result from parametric instabilities, mode interactions, or transition bypass mechanisms (a term commonly used to identify transition modes which bypass the linear growth process of disturbances). When vehicle surface roughness are present (a typical bypass). it is believed that facility noise from conventional tunnels has little effect on transition. Experimental studies have suggested that while noise may have little effect for roughness heights large enough to be considered effective ${ }^{(i)}$ (turbulence initiated immediately downstream of the roughness element site). there still may be an influence of wind tunnel noise on transition onset data derived from roughness that are less than effective ${ }^{62-6,63}$. Based upon experimental evidence suggesting the susceptibility of less than effective roughness elements to acoustic disturbances, quantification of the conventional facility disturbance environment is essential.

\section{Experimental Methods}

Models

The present tests in the LaRC 20-Inch Mach 6 Air Tunnel utilized two models that were originally constructed for testing in the LaRC Mach 6 NTC Quiet Tunnel. The original stability experiments were to be conducted on a 25 -inch long (sharp tip) 5-degree straight cone model shown schematically in Fig. Ia. Undocumented surface temperature measurements made on the 5-degree straight cone in the LaRC Mach 6 NTC Quiet Tunnel revealed that boundary layer transition onset did not occur.

Consequently, the emphasis of the stability tests shifted to the second conical model (with a flared base). The purpose of the flare was to promote boundary layer instability via an adverse pressure gradient to insure transition would occur on the model within the limited quiet flow Reynolds number capability of the Mach 6 NTC Quiet Tunnel.

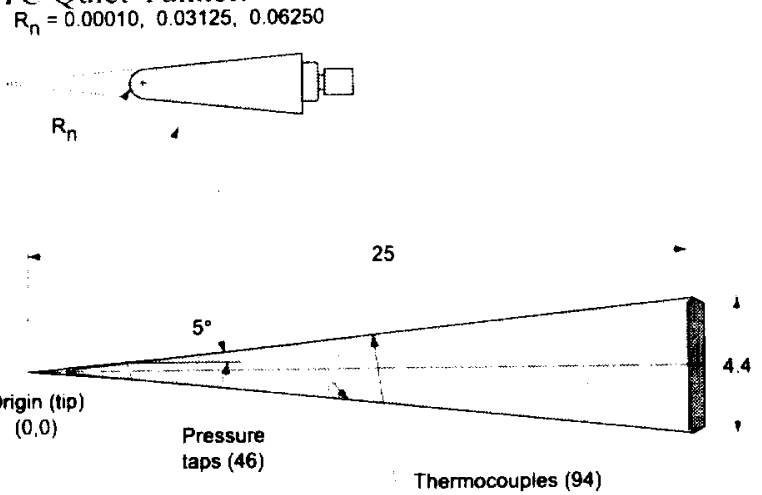

(a) 5 deg straight cone and nosetip

dimensions (inches)

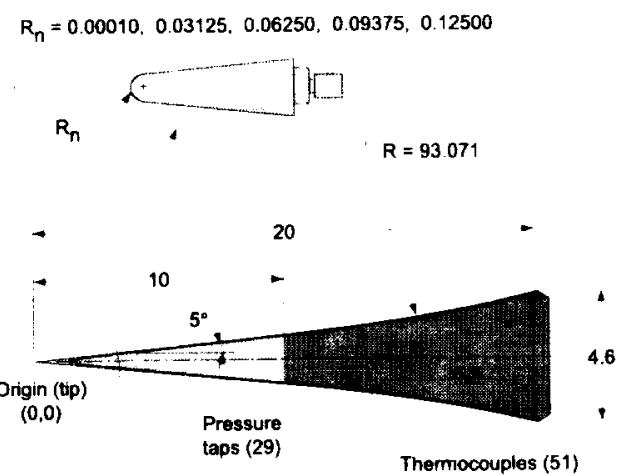

(b) 5 deg flared cone (Model 93-10) and nosetip dimensions (inches)

Fig. 1. Schematic diagram of slender cone models.

A schematic diagram of the flared cone model geometry is shown in Fig. 1b. Measuring 20-inches in length (sharp tip) the model base diameter is 4.6-inch. The first 10-inch section of the model consists of a 5 degree half angle cone followed by a 10-inch section comprised of an outward flare. Tangency was specified at the cone/flare junction. An arc radius of 93.07-inches defined the flare curvature. Details of the 5-degree half angle flared cone model (designation 93-10) can be found in Ref. 16.

Both models were constructed thin walls fabricated from 15-5 stainless steel to reduce surface heat conduction effects and to bring the models to thermal equilibrium as quickly as possible during a run. The flared cone model was constructed with five interchangeable nosetips $\left(R_{n}=0.0001,0.03125\right.$, $0.06250,0.09375$, and 0.125 -inch) fabricated from 13-8 stainless steel (see Fig. la-b) while the straight cone had three nosetips $\left(R_{11}=0.0001,0.03125,0.06250\right)$. The surface finish on both models was originally highly polished to minimize waviness and roughness induced 
the flow was limited to 20 seconds. A detailed description of this facility maly be found in Ref. 64

In an attempt to attenuate noise from upstream piping/air control valves, the settling chamber was enlarged and recently retrofitted with a series of acoustically damping porous screen elements. This technology $y^{7}$ was based upon quiet tunnel experience at LaRC and was designed to reduce pressure fluctuations in the settling chamber to approximately $0.005 \%$ of the stagnation pressure.

Mass flow and total temperature fluctuations were measured in this facility ${ }^{65}$ at reservoir conditions $\left(P_{0}=125\right.$ psia and $T_{10}=410$ degree $F$.) very close to the reservoir conditions associated with the quiet tunnel low disturbance condition $\left(P_{10}=1.30\right.$ psia and $T_{10}=350$ degree F.). In that work. a dual wire constant temperalure anemometer was used to infer mass and lotal temperature fluctuations of $2.4 \%$ and $1.4 \%$, respectively. Freestream spectra from this study at 125 psia began to roll off at approximately $10 \mathrm{kHz}$ with little measurable fluctuations above the electronic noise floor out to the limits of the measurement near 160 $\mathrm{kHz}$. As discussed in Ref. 65, the mass fluctuations were converted to pressure fluctuations and were quoted as $3.4 \%$. which the authors claim was comparable to the results of Ref. 66 which reported $2.8 \%$ using a pitot probe. These quantitative measurements were made prior to the addition of the acoustically damping porous screen elements in the settling chamber and should be repeated.

Mach 6 Nozle Test Chamber Quiet Tunnel: Heated and dried air was used as the test gas. Typical low disturbance operating conditions for the tunnel were: stagnation pressures ranging from 80 to 130 psia, stagnation temperatures up to 350 degree $F$, and a maximum freestream unit Reynolds numbers of 2.8 million per foot. A contoured axisymmetric slow expansion nozzle was used to provide a nominal freestream Mach number of approximately 5.9. The nozzle exit diameter was 7.49 inches with the flow exhausting into an open jet test section: the nozzle throat diameter was 1.0-inch. This facility had no model injection system thus transient based heat transfer measurements could not be obtained. Run time for the adiabatic wall temperature measurements varied between 30 and 60 minutes. Details conceming the facility, the size of the quiet flow envelope and measurements of the disturbance environment are discussed in Ref. 12.

\section{Test Conditions and Setup}

Reservoir and corresponding free stream flow conditions for the present tests in the LaRC 20-Inch Mach 6 Air Tunnel are presented in Table 1 . The quiet tunnel test condition is represented at $P_{0}=130$ psia and $T_{0}=350$ degree $F$. The freestream properties were determined from the measured reservoir pressure and temperature and the measured pitot pressure at the test section. The standard procedure used to compute flow

conditions for the ALC facilities uses the viscosity formulation given by Chapman-Cowling and is detailed in Ref. 67. However, for the present test the computed Reynolds number was based upon the less accurate Sutherland formulation for viscosity to maintain consistency with the method employed to compute flow conditions for tests made in the LaRC Mach 6 NTC Quiet Tunnel. Computed Reynolds numbers based upon Sutherland's formulation are generally $5 \%$ lower relative to that inferred from Chapman-Cowling.

In the present test, the ratio of model base area to tunnel cross sectional area for the cone flare model (9310) was 0.042 and 0.036 for the straight cone. In both wind tunnel experiments a base mounted cylindrical sting supported the conical models. A limited number of runs were made with an uncalibrated hotwire positioned in the freestream just outside the model shock layer. The probe was attached to a holder that was mounted to the cylindrical sting. Model angle-ofattack (pitch) and sideslip (yaw) were referenced to the geometric centerline of the tunnel and were set to zeno in the tunnel using a combination of accelerometer based angular measurements and a laser alignment system. It should be recognized that geometric pitch and yaw angles may not represent actual flow pitch and yaw angles if flow angularity is present. A photograph of the sting supported cone flare model is shown in Fig. 2. Details of the cone flare model installation in the NASA LaRC Mach 6 NTC Quiet Tunnel can be found in Ref. 16.

\section{Test Techniques}

Adiabatic wall temperature: In the original stability experiments conducted in the low disturbance tunnel, the individual thermocouple temperature measurements were monitored with time and used to determine when the model had obtained a state near thermal equilibrium. The resulting temperature distribution was used to identify transition onset. The test procedure for the quiet tunnel measurements involved preheating the model by exposing it to hypersonic conditions for 30 to 60 minutes to achieve thermal equilibrium. For the adiabatic wall temperature measurements in the conventional tunnel test, the test procedure was designed to approximate as closely as possible this technique. That is, the model was injected into the hypersonic stream and allowed to reach a state near thermal equilibrium. Higher mass flow rates with the present conventional tunnel tests limited total run times to approximately 12 to 1.5 minutes depending on the desired Reynolds number. Temperature time histories obtained during each run were monitored and indicated when thermal equilibrium was approached. Typical time rate of change of temperature near thermal equilibrium was on the order of 0.5 degree per minute. At the low Reynolds number laminar conditions $\left(\operatorname{Re}_{x} \leq\right.$ $1.1 \times 10^{\mathrm{f}}$ ) this criteria could not be reached and required that the model be preheated prior the start of the run. 
The ESP pressure measurement system was calibrated prior to each run. The measured surface pressure was expressed in nondimensional form, $P / P_{x}$, and in terms of a pressure coefficient. Measured reservoir values of $P_{0}$ and $T_{0}$ are estimated to be accurate to within \pm 2 percent.

The accurate determination of angle of attack was of utmost importance for the present slender cone tests as small model angles of attack relative to the flow can have a large effect on the theoretically computed frequency of the most unstable second-mode disturbance 26. The angle of attack of the cone models was set to zero degrees by placing two calibrated accelerometer based inclinometers along the 0 and 180 degree rays of the cone surface. A model incidence of zero degrees was inferred when the absolute angular magnitude of both inclinometers was equal. Uncertainties in model angleof-attack associated with accelerometer based measurements are estimated to be \pm 0.07 degree. As shown in Fig. 3, rolling the model 180 degrees produced no changes in the heating distribution and indicated that flow angularity was not an issue. Based on schlieren images, the model incidence was observed to change by no more than 0.05 degree due to thermal gradients in the support hardware during the long duration runs. The sideslip angle of the cone models was set to zero degrees by alignment of a laser light sheet along the longitudinal array of pressure orifices. Uncertainties in model sideslip angle associated with optical based measurements are estimated to be \pm 0.2 degree.

\section{Computational Methods}

Preface

Mean flow computations associated with the sharp nose conical models were performed with two Navier-Stokes solvers. LAURA, the benchmark code of the Aerothermodynamics branch at NASA LaRC, was used to provide straight cone surface heating predictions for comparison with laminar and turbulent measurement. Predictions provided by CFL3D were used to obtain boundary layer profile inputs used in the subsequent boundary layer stability analysis on the flared cone.

\section{Mean Flow Calculations - LAURA}

Computations were performed using the LAURA $^{7(1-7)}$ code (version 4.9.2). The LAURA (Langley Aerothermodynamic Upwind Relaxation Algorithm) code is a three-dimensional, finite-volume solver which includes perfect-gas, equilibrium and nonequilibrium chemistry models, and can be used to solve the inviscid, thin-layer Navier-Stokes, or full NavierStoke equations. For the current study, the thin-layer Navier-Stokes equations were solved. Laminar computations were performed to determine heating rates for comparison with the laminar wind tunnel data, and to obtain boundary layer edge-parameters for future correlations. Turbulent computations were performed for comparison with turbulent wind tunnel data using the algebraic Baldwin-Lomax ${ }^{72}$ model with modifications ${ }^{73}$ for compressible flow and either a zerolength or Dhawan-Narashima ${ }^{7+}$ transition length model. The transition onset location for the computations was determined from the wind tunnel data. Solutions were computed on an axisymmetric, single-block (101 x 65) point grid. Grid adaptation was performed to align the bow-shock with the grid and produced nominal wall cell Reynolds numbers on the order of 10 . Freestream conditions for the LAURA wind tunnel computations were set to the freestream operating conditions of the current test, which are listed in Table 1. For the wind tunnel computations, a uniform, ambient 80 degree $F$ model wall temperature boundary condition was imposed.

\section{Mean Flow Calculations - CFL 3D}

Mean flows around the cone used in the stability predictions were computed using CFL 3D ${ }^{75} 76$, which solves the compressible, three-dimensional, thin-layer Navier-Stokes equations with a finite-volume formulation. The code is characteristic-based. where upwind-biased spatial differencing is used for the inviscid terms. The flux-difference-splitting method of Roe ${ }^{77}$ was used to obtain fluxes at the cell faces. All viscous terms were centrally differenced. The coxde provides for a variety of techniques that were used to accelerate convergence to steady state. In addition to local time-stepping, grid sequencing and multi-gridding were used. Grid sequencing allows the user to establish a converged or partially converged solution on a coarser grid before proceeding to a finer grid level. Multigridding is used to eliminate long-wavelength errors on the finer grids, and thereby improve convergence.

Except where indicated, the calculations were performed using adiabatic wall conditions on the cone surface. Extrapolation was used as the downstream (outflow) boundary condition and the free stream conditions specified in Table 1 were specified upstream of the cone and were used as the far-field condition. The shock was always captured within the domain.

The calculations were performed using a singleblock grid with 137 nodes in the streamwise direction and 257 nodes in the cross-stream direction. The flow was forced to be axisymmetric by computing only a single azimuthal cell with width of 1 degree and periodic boundary conditions. Seven nodes of the streamwise grid are upstream of the nose of the cone: the eighth node coincides with the sharp cone tip. Four levels of multi gridding were applied at the finest grid. At least 50.000 iterations were used on the finest grid for each calculation. Additional iterations resulted in negligible changes to the computed flow.

At a unit Reynolds number of $6.2 \times 10^{6} / \mathrm{ft}$ (not shown), the results using the full grid were compared with the results using a grid consisting of every other point in the streamwise and cross-stream directions. A pointwise comparison of the computed velocities 
number, the transition peak is clearly observed but typically becomes more difficult to identify as transition onset moves aft (e.g. lower Reynolds number or increased nose bluntness). The transition peak is often identified with the end of transition and hence the establishment of fully developed turbulent flow. Inspection of Fig. 4 a suggests that the point of fully developed turbulent flow lies some distance downstream of the measured transitional peak and is consistent with the experimental observations of Refs. 52 and 82 . This distinction, however, between the transition peak and fully developed turbulent flow is of importance when validating $C F D$ turbulent heating prediction.

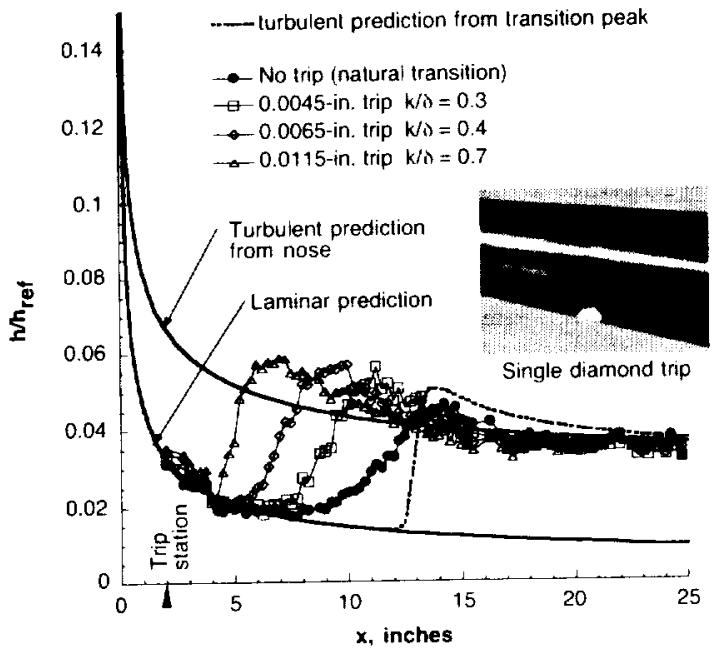

(b) $\mathrm{Re}_{x}=4.3 \times 10^{6} / \mathrm{ft}$

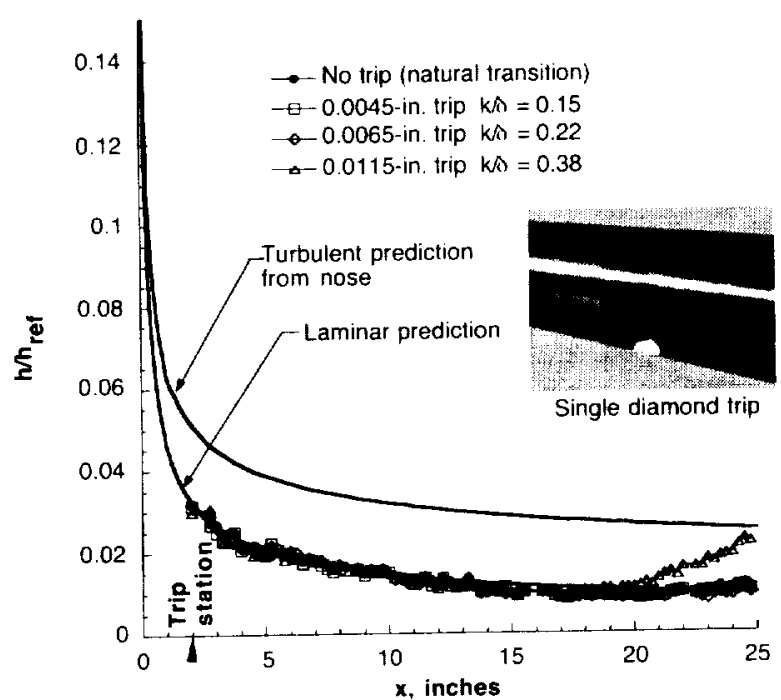

(c) $\operatorname{Re}_{x}=1.1 \times 10^{\prime} / \mathrm{ft}$

Fig. 4. Comparison of measured smooth and discrete trip heating distributions with laminar and turbulent prediction, $5 \mathrm{deg}$. straight cone, $M_{\infty}=6$ (conventional), $\alpha=0$ deg, $R_{n}=0.0001-i n$.
In Fig. 4b, natural "smooth" body transition at $\operatorname{Re}_{\mathrm{x}}=4.3 \times 10^{6} / \mathrm{ft}$ has been compaued to transition forced with discrete boundary layer trips. The ratio of trip-toboundary layer height $(\mathrm{k} / \mathrm{\delta})$ varied from 0.3 to 0.7 . As expected. the larger trip heights are more effective at bringing transition onset closer to the trip location $(x=2-i n)$. Typical of all forms of roughness tested in the present study, agreement between the measured smooth wall and the forced turbulent heating with turbulent prediction was generally better than $\pm 5 \%$. In Fig. 4c natural "smooth" body transition at $R_{e}=1.1 x$ $10^{6} / \mathrm{ft}$ was not observed. The largest trip had only a marginal effect. Laminar heating predictions were generally within $5 \%$ of measurement.

\section{Wall Temperature Ratio and Revnolds Number Effects}

The heating distributions in Fig. 4 were infered from temperature-time measurements whereby the model residence time in the flow was only a few seconds. The model wall temperature under adiabatic conditions (separate run-residence time in flow approximately 14 minutes) was, naturally, higher than that measured with the transient heating technique. Wall temperature can affect hypersonic transition. In the context of linear stability theory, hypersonic boundary layers on a slender cone near $M_{x}=6$ would have both first and second mode disturbances. Wall cooling would be expected to stabilize first mode disturbances while destabilizing the second mode $e^{x 3-84}$.

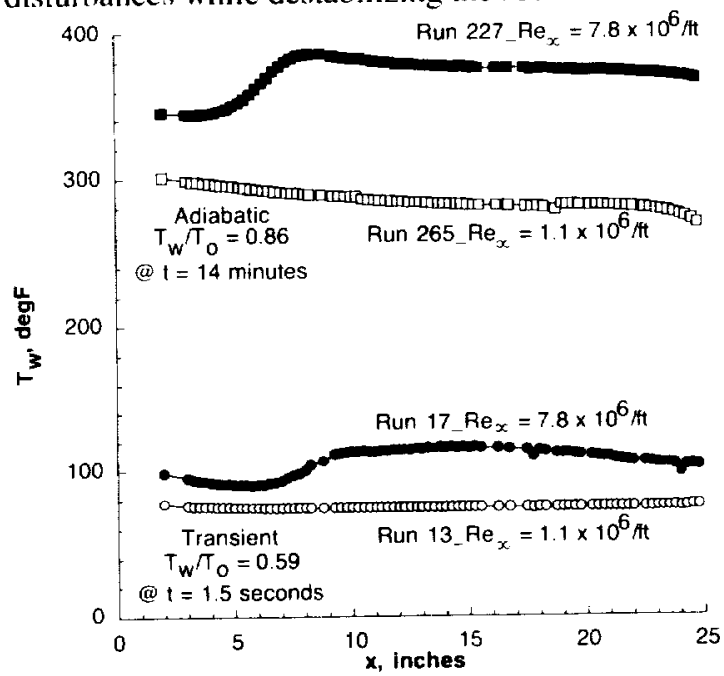

Fig. 5. Comparison of model temperature distributions for recovery temperature (adiabatic wall) and transient heating measurements, 5 deg. straight cone, $M_{\infty}=6$ (conventional), $\operatorname{Re}_{\infty}=1.1$ and $7.8 \times 10^{\%} / \mathrm{ft}$, $\alpha=0$ deg, $R_{n}=0.0001-i n$.

A correlating parameter often used is the wall-tototal temperature ratio, $T_{4} / T_{11}$. The manner in which $T_{w} / T_{1}$ is varied can impact the transition process in a ground based tunnel. Changing the stagnation temperature to produce a variation in $T_{4} / T_{4}$, would likely 
downstream of that inferred from the adiabatic wall temperature distribution $\left(\mathrm{T}_{\mathrm{w}} / \mathrm{T}_{4}=0.86\right)$. This was not the anticipated trend whereby a decrease in $T_{n} / \Gamma_{1}$ would be expected to destabilize the second mode resulting in it forward movement in the location of transition onset. It should be also noted that in several investigations conducted in conventional hypersonic facilities ${ }^{51}$ little change in transition onset Reynolds numbers for $.59<\mathrm{T} / \mathrm{T}_{0}<0.86$ were reported. Further discussion is deferred to the section devoted to correlation of measurement to linear stability prediction.

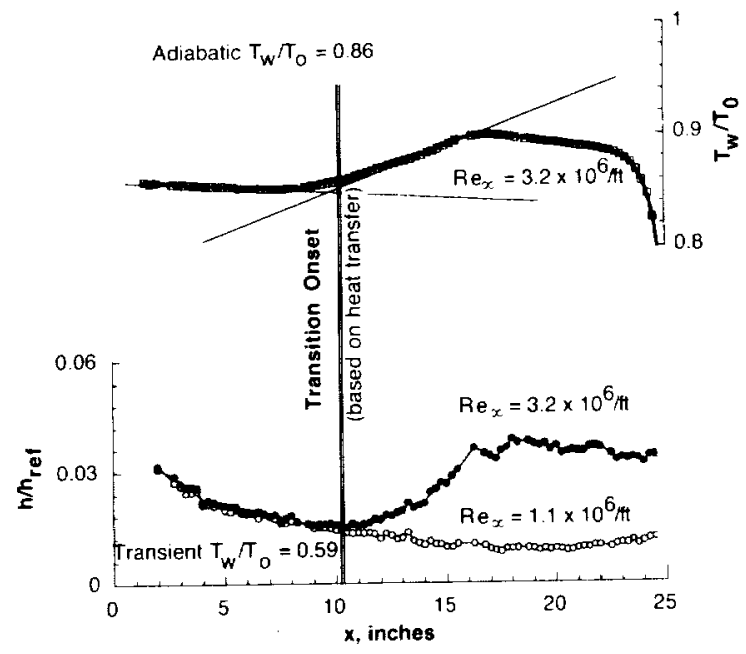

(e) $\operatorname{Re}_{x}=3.2 \times 10^{\prime} / \mathrm{ft}, \mathrm{P}_{4}=180 \mathrm{psi}, \mathrm{T}_{0}=450$ deg $\mathrm{F}$

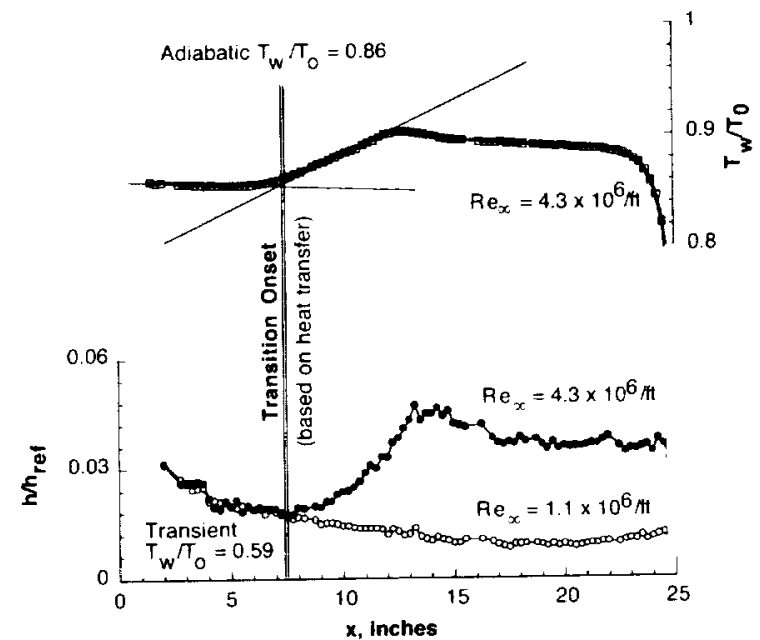

(f) $\operatorname{Re}_{x}=4.3 \times 10^{6} / \mathrm{ft}, \mathrm{P}_{0}=250 \mathrm{psi}, \mathrm{T}_{\mathrm{o}}=450$ deg $\mathrm{F}$

As expected, an increase in Reynolds number, Fig. 6a-h, moved the transition onset point on the cone surface upstream. The first indication of a transition peak (localized maximum in the nondimensionalized heating distribution) occurred at $\operatorname{Re}_{x}=4.3 \times 10^{\prime \prime} / \mathrm{ft}$.

At $\operatorname{Re}_{x}=2.8 \times 10^{6} / \mathrm{ft}$, the nominal reservoir temperature and pressure conditions corresponding to the quiet tunnel condition were 350 degree $F$ and 130 psia. respectively. This relatively low temperature reservoir condition had been selected to reduce hot-wire overheat requirements for that test series. Concerns that this quiet tumnel operating condition lie too close to the air liquefaction curve were assessed in the conventional tunnel by testing at different reservoir pressure/temperature combinations so as to hold $\operatorname{Re}_{x} / \mathrm{tt}$ constant at $\operatorname{Re}_{x}=2.8 \times 10^{6} / \mathrm{ft}$. The largest difference in transition onset, Fig. 6c-d. was approximately 0.25-in. and was considered insigificant.

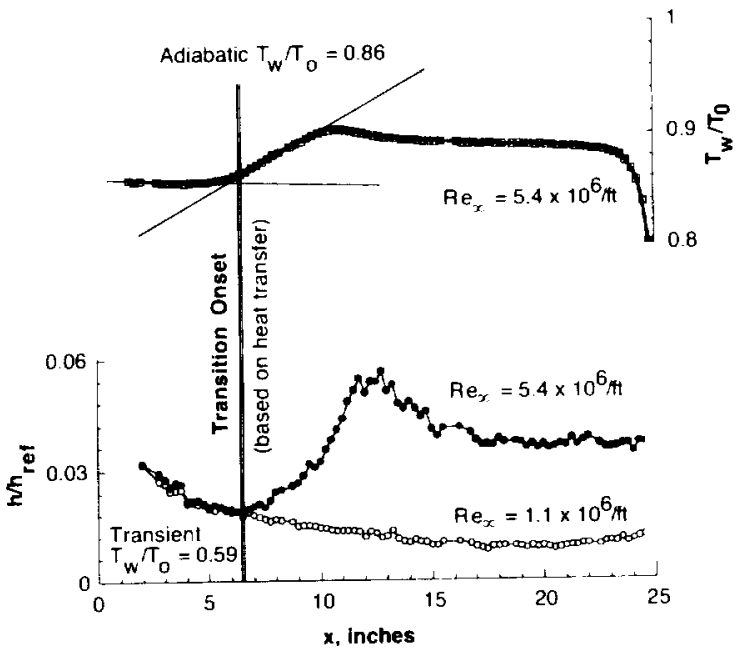

(g) $\operatorname{Re}_{x}=5.4 \times 10^{6 /} / \mathrm{ft}, \mathrm{P}_{0}=325 \mathrm{psi}, \mathrm{T}_{6}=475$ deg $\mathrm{F}$

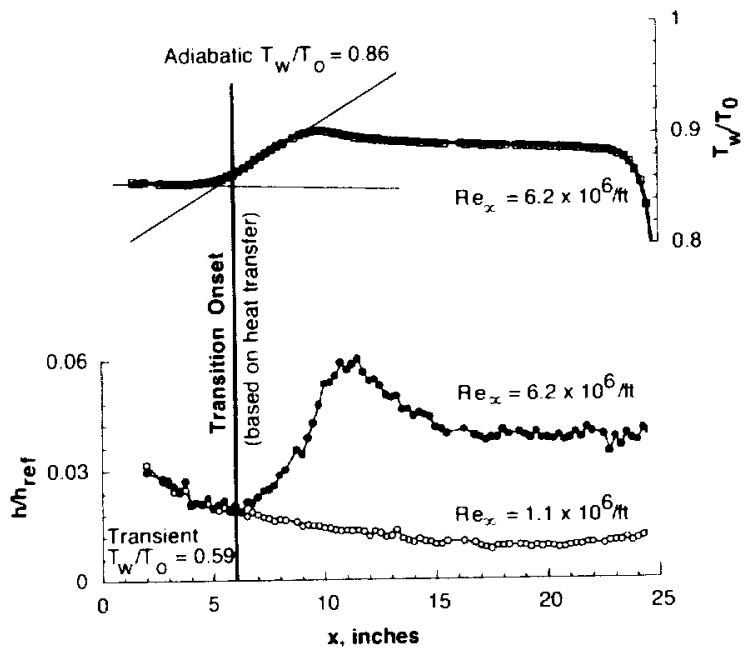

(h) $\operatorname{Re}_{x}=6.2 \times 10^{6} / \mathrm{ft}, P_{0}=365 \mathrm{psi} . \mathrm{T}_{0}=475 \mathrm{deg} F$

Fig. 6. Comparison of smooth body transition onset inferred from heating distributions with those determined via wall recovery temperature 5 deg. straight cone, $M_{\infty}=6$ (conventional), $\alpha=0$ deg, $R_{n}=0.0001 \cdot$ in.

\section{Bluntness Effects}

While primarily intended to provide data for comparison to the quiet tunnel results. the present conventional tests also served to assess the effects of nose bluntness and angle of attack on transition onset.

\section{1}

American Institute of Aeronautics and Astronautics 
differences in $\theta_{c}$ and $\mathrm{Re}_{\mathrm{k} . .1}$ exist between the data sets it is difficult to quantify the differences in magnitude.

The variation of the normalized transition location on the windward ray with angle of attack for the blunted cone exhibited a different trend than the sharp cone and are consistent with Stetson (Ref. 49).

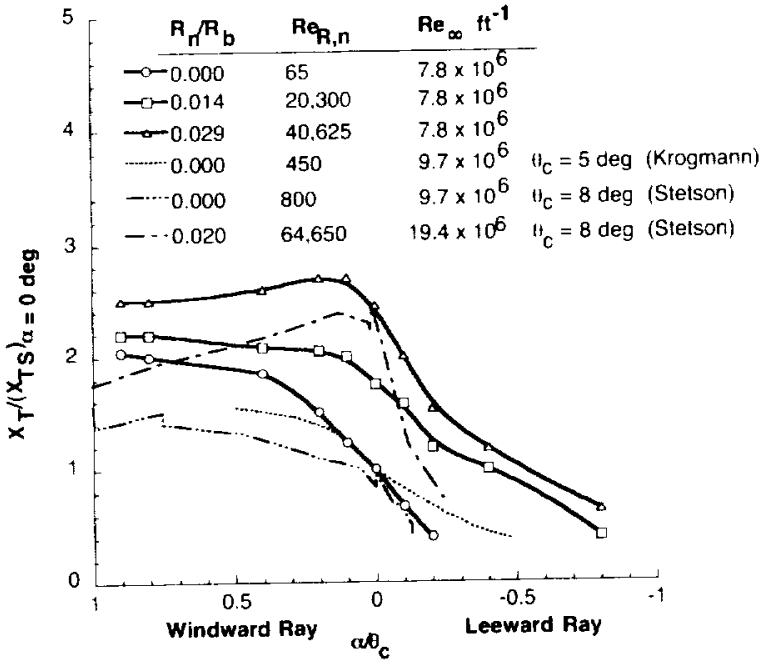

(a) $\operatorname{Re}_{x}=7.8 \times 10^{\prime 1} / \mathrm{ft}$, Krogmann $M_{x}=5$. (Ref.47); Stetson $M_{x}=5.9($ Ref.49)

At the time. Stetson postulated that the effects of bluntness diminished with increasing angle of attack. thus the location of transition onset for the blunt nosetips would eventually cease to move rearward at some small incidence angle. In the present test, the location of transition onset for the bluntest nosetip $\left(R_{n}\right.$ $=0.125$-in and $\left.\operatorname{Re}_{\mathrm{R} . \mathrm{n}}=40.625\right)$, Fig. 8a, initially moved rearward for $\alpha / \theta_{c}<0.2$ (hence the increased laminar running length with increasing incidence).

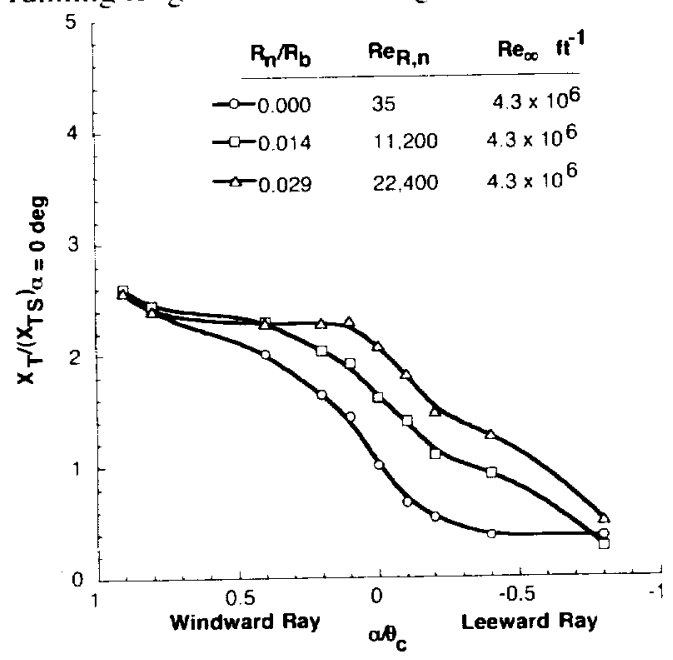

(b) $\operatorname{Re}_{x}=4.3 \times 10^{6} / \mathrm{ft}$

Fig. 8. Nose bluntness and angle of attack effects on windward/leeward-ray smooth body transition locations. Normalized to sharp cone values, 5 deg. straight cone, $M_{\infty}=6$ (conventional)
In contrast to the sharp cone trend where transition continues to move rearward. the transition onset location for this bluntest nosetip reversed and began to move forward as incidence angle was further increased $\left(\alpha / \theta_{c}>0.2\right)$. At that time. Stetson conjectured that the blunt cone angle of attack trends (curves) would turn and eventually approach the sharp cone levels. The behavior postulated by Stetson was exhibited by the present data, Fig. $8 b$, for $\operatorname{Re}_{x}=4.3 \mathrm{x}$ $10^{6} / \mathrm{ft}$. Stetson's bluntness parameter was $R_{n} / R_{b}$ and did not account for Reynolds number effects.

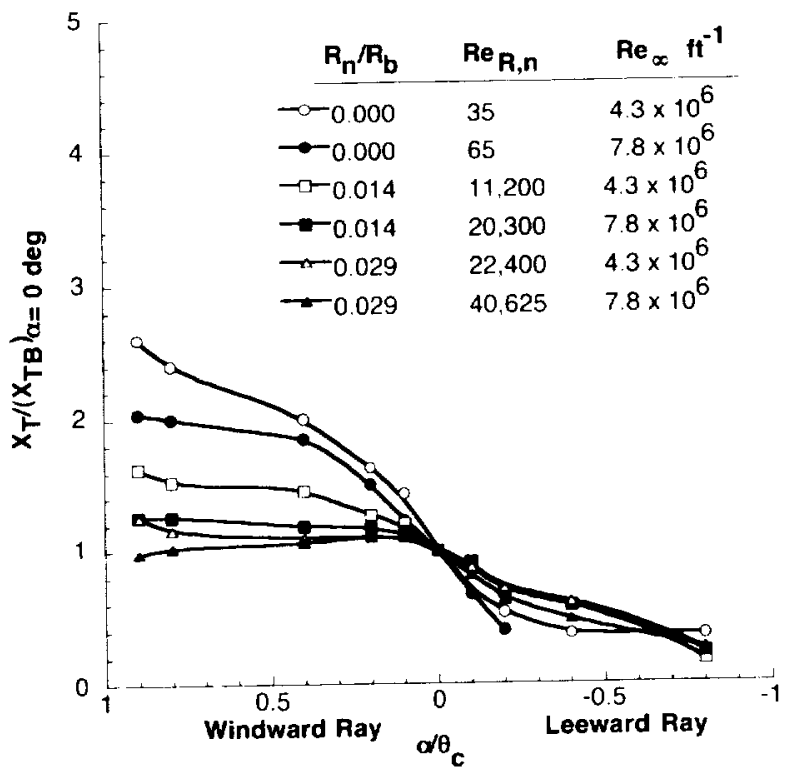

Fig. 9. Nose bluntness and angle of attack effects on windward/leeward-ray smooth body transition locations. Normalized to blunt cone values, 5 deg. straight cone, $M_{\infty}=6$ (conventional)

In Fig. 9. the windward and leeward transition onset locations presented in Fig. 8a-b have been renormalized to the location measured on the corresponding blunt nosetip at $\alpha=0$ degree. Expression of angle of attack trends in windward transition onset location in terms of the nose bluntness Reynolds number $\left(\operatorname{Re}_{\mathrm{R} . n}\right)$ suggest that angle of attack effects $\left(\alpha / \theta_{c}<1\right)$ on transition onset appear to be mitigated for $\operatorname{Re}_{\mathrm{R}, \mathrm{n}}>20,000$.

\section{Conventional Hypersonic and Low Disturbance Supersonic Comparisons}

The effects of tunnel noise on high-speed laminar -turbulent transition are well documented and Schneider ${ }^{5}$ presents an excellent review. When comparing hypersonic parametric trends inferred from measurements on a slender cone to those obtained at supersonic conditions, one must keep in mind that different instability mechanisms are most likely present. At supersonic conditions first mode instabilities prevail. while at the hypersonic conditions of the present tests. 
tunnel boundary layer bleed slots. King observed that under supersonic low disturbance conditions, increases in angle of attack above $\alpha / \theta_{c}>0.12$ did not produce a rearward movement of windward transition onset as was inferred from measurements under "noisy" conditions. The present $M_{x}=6$ conventional hypersonic tunnel data were obtained at $\operatorname{Re}_{x}=7.8 \times 10^{6} / \mathrm{ft}$ and did not exhibit this behavior. As in Fig. 10, this unit Reynolds number was selected so as to ensure transition on the flared cone occurred upstream of the flare adverse pressure gradient $(x=10$-in.) and transition onset measurements made on both the straight cone and the flared cone could be presented. For these tests conducted at supersonic and hypersonic conditions. $\operatorname{Re}_{\mathrm{R} . \mathrm{n}}<1.500$. Curve fits to the data have been applied to clarify trends. It is clear that the conventional tunnel exhibited the same parametric trend as the supersonic data at "noisy" conditions. In this special case, the parametric trend from the conventional tunnel appears to be opposite to that inferred from the supersonic low disturbance tunnel. The trends displayed in the supersonic low disturbance facility remain inconclusive as the aft end of the cone was outside the region established as "quiet".

Comparison of Hypersonic Transition Onset in a Conventional and a Low Disturbance Facility

A direct comparison of conventional vs. low disturbance tunnel transition onset locations at adiabatic wall conditions for the straight and flared cone at comparable freestream conditions is shown, Fig. 12a-b, for $\operatorname{Re}_{x}=2.8 \times 10^{\circ} / \mathrm{ft}$. To the author's knowledge this represents the first comparison of transition onset location between a conventional and low disturbance hypersonic tunnel utilizing common models and transition detection techniques.

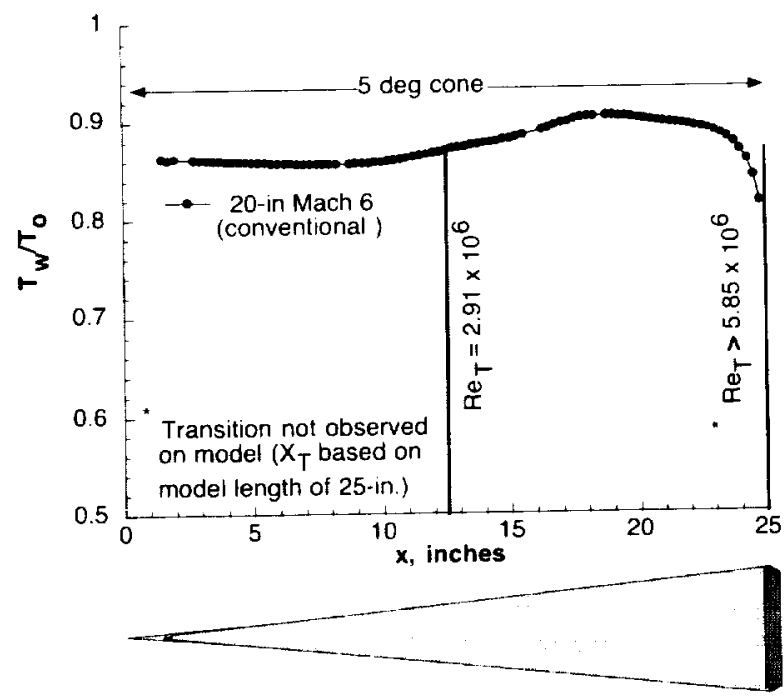

(a) 5 deg cone.

The conventional tunnel straight cone transition onset location (Fig. 12a) inferred from the wall temperature distribution near adiabatic conditions was located $x=12.5$-in. at a comesponding transition Reynolds number $\left(\operatorname{Re}_{\mathrm{f}}\right)$ of $2.91 \times 10^{\prime \prime} / \mathrm{ft}$. The method for estimating transition onset via the adiabatic wall temperature distribution was consistent with that used for tests in the quiet tunnel and consisted of determining the intersection of two straight lines passing through the laminar region and the sharp temperature rise near the transition peak (see Fig. 6d) as discussed in Ref. 16. At the corresponding unit Reynolds number in the Mach 6 Nozzle Test Chamber Quiet Tunnel, the boundary layer on this same model remained completely laminar ${ }^{16}$. Thus, based upon the 25-in. model length $\mathrm{Re}_{\mathrm{T}} \geq 5.85 \times 10^{6}$. The transition onset Reynolds number under low disturbance conditions is a factor of 2 or more relative to that measured on a straight cone in the LaRC conventional hypersonic tunnel. This is comparable to the factor of 2.3 measured on a straight cone by Ref. 9 at supersonic "quiet" and "noisy" conditions. Unfortunately, the hypersonic low disturbance tunnel was not operated "noisy" for the limited tests conducted with the straight cone model and a direct comparison to a conventional tunnel measurement cannot be made.

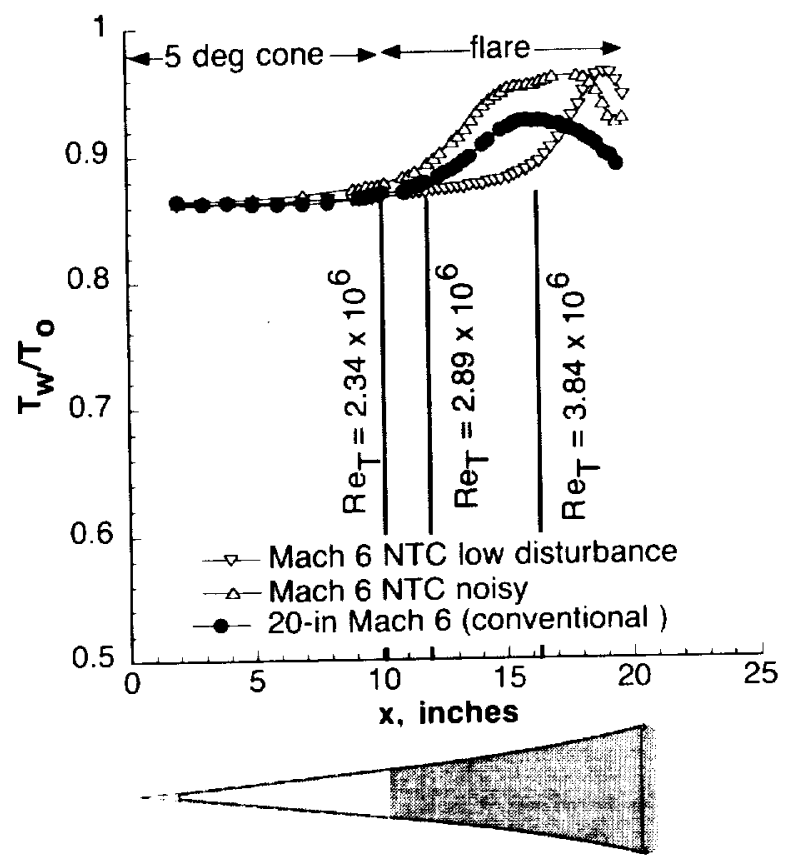

(b) 5 deg flared cone

Fig. 12. Comparison of present smooth body transition onset locations to that obtained in the NASA LaRC $M=6$ NTC Quiet Tunnel at low and high disturbance levels. $M_{\infty}=6$, $\operatorname{Re}_{\alpha}=2.8 \times 10^{6} / \mathrm{ft}, \alpha=0 \mathrm{deg}, R_{n}=0.0001-\mathrm{in}$.

Because transition on the straight cone was not observed in tests conducted in the Mach 6 Nozzle Test Chamber Quiet Tunnel, emphasis of the stability tests was placed on the flared cone. The flare was designed to produce a nearly constant boundary layer thickness that was expected to enhance the likelihood of transition via 
cone in Fig. 13a. For $\mathrm{Re}_{x} / \mathrm{m} \geq 9 \times 10^{\circ}$ the straight cone and flared cone transition onset Reynolds numbers are very consistent despite the lower thermocouple spatial resolution on the flared cone model (and increased uncertainties in transition onsel location) Above this value of $\mathrm{Re}_{\mathrm{T}}$, transition onset has occurred on the cone section of the flared cone and transition onset locations between the two models should be identical. As expected, below $\mathrm{Re}_{\mathrm{x}} / \mathrm{m}=9 \times 10^{\prime \prime}$ a disparity between the transition onset Reynolds number for the two conical models developed due to the influence of the flare. At the lowest unit Reynolds number, the straight cone boundary layer was wholly laminar while the flare adverse pressure gradient has presumably destabilized the boundary layer and promoted transition on the model.

Linear stability theory at supersonic conditions suggest that transition should occur on cones at length Reynolds numbers that are lower than on flat plates. Measurements made in a low disturbance environment (namely the LaRC supersonic quiet tunnel" not shown) are consistent with this prediction and have shown coneto flat plate transition Reynolds number ratios less than unity-in the range of 0.8 to 0.9 . In contrast. experimental data obtained in conventional tunnels have historically shown the opposite trend. Specifically. measurements at supersonic Mach numbers in conventional tunnels ${ }^{\text {xo }}$ have indicated cone-to flat plate transition Reynolds number ratios greater than unity-in the range of 2.2 to 2.5 (and 1.6 to 1.9 for $M_{x}=6$ ). As suggested by Beckwith (Ref. 7) the observation that $\mathrm{Re}_{\mathrm{T} \text {, conc }} / \mathrm{Re}_{\mathrm{T} \text { plate }}<1$ (for conventional tunnels) may be due to the faster boundary layer growth on a flat plate relative to a cone and thus, stronger receptivity of the flat plate to the incident acoustic field from the turbulent test section walls found in the conventional tunnels.

Consistent with historical observations, the present data from the Mach 6 conventional tunnel $\left(\mathrm{Re}_{x} / \mathrm{m} \leq 1 \times 10^{7}\right)$ indicate that the straight cone and flared cone transition onset Reynolds numbers were higher than the corresponding flat plate data (see Fig. $13 \mathrm{~b}$ ) and hence would yield cone-to flat plate transition Reynolds number ratios greater than one. However, for $\mathrm{Re}_{\mathrm{x}} / \mathrm{m} \geq 1 \times 10^{7}$ the present data show that the straight cone and flared cone transition onset Reynolds number was actually lower than or nearly equal to that measured on the flat plate (see Fig. 13b) and hence would yield cone-to flat plate transition Reynolds number ratios less than one. Ironically, this observation at higher Reynolds numbers at hypersonic edge Mach numbers, is somewhat consistent with those made in the supersonic low disturbance tunnel. As noted in Ref. 5, the LaRC supersonic low disturbance tunnel run "noisy" also yielded cone-to flat plate transition Reynolds number ratios less than one (opposite to what was expected via Pate' ${ }^{x+1}$ cone-to-flat plate transition findings) and was never fully explained.
In general, the flat plate transition onset Reynolds numbers from the conventional LaRC Mach 6 tunnel are consistently higher than the flat plate $M=3$ and 3.7 data from the AEDC and JPL facilities. Since it has been shown that the disturbance field sound intensity correlates with test section size ${ }^{x / 1}$ one might expect better agreement of the present smooth flat plate $\mathrm{Re}_{\mathrm{T}}$ data to the JPL results. Despite the similar test section dimensions to the JPL tunnel, other factors such as Mach number effects on radiated tunnel wall noise. boundary layer receptivity on the flat plate, or the noise reduction technology in the conventional tunnel sellling chamber may all have contributed to the higher $\mathrm{Re}_{1}$ values measured on the flat plate in the conventional LaRC 20-Inch Mach 6 Air Tunnel.

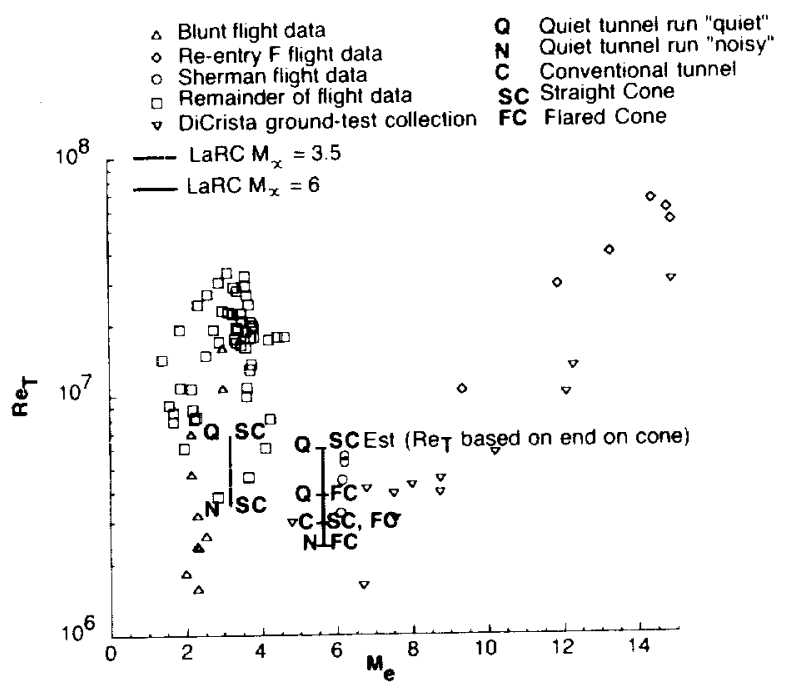

Fig. 14. Comparison of transition onset Reynolds number on sharp cones near zero angle of attack in flight and ground test as reported in (Ref. 86) with present data.

Figure. 14 (adapted from Fig. 1 of Ref. 86) shows both flight and ground based transition Reynolds numbers for a range of edge Mach number (see Ref. 86 for citations of these datasets). Variations of this figure are often used to indicate the inability of conventional ground facilities to properly simulate free flight conditions due to the higher disturbance levels generated from radiated noise from wind tunnel walls. It also shows an increase in transition onset Reynolds number with increasing Mach number suggested by flight and ground based measurements. The figure has been modified to include the present straight cone and flared cone results obtained at $\mathrm{M}_{\mathrm{c}}=5.4$. Transition onset Reynolds numbers from the LaRC conventional hypersonic tunnel are generally consistent with the ground measurements reported by DiCrista (see Ref. 86) for sharp cones near $\alpha=0$ degree and the flight results of Sherman (see Ref. 86). 
factor for the most unstable first mode frequency was not much smaller than that predicted for the second mode ( 2 versus 3.8 ) but such an explanation is purely conjecture. A small $\mathrm{N}$-factor at transition onset may also suggest that early nonlinear interaction could be present in the conventional wind tunnel due to a higher disturbance environment. An earlier investigation ${ }^{\mathrm{k}}$ ? using nonlinear PSE indicated that nonlinear effects were important for the Mach 8 sharp cone experiment conducted by Ref. 88 . For the present experiment. nonlinear interactions involving both second-mode and asymmetric first-mode disturbances may contribute to transition. It is also possible that transition in the conventional tunnel may be the result of nonlinear mode interactions $s^{2 x}$ and interpretation of the results based on linear stability theory may not be adequate. Further studies, both experimental and computational. are necessary to clarify these issues.

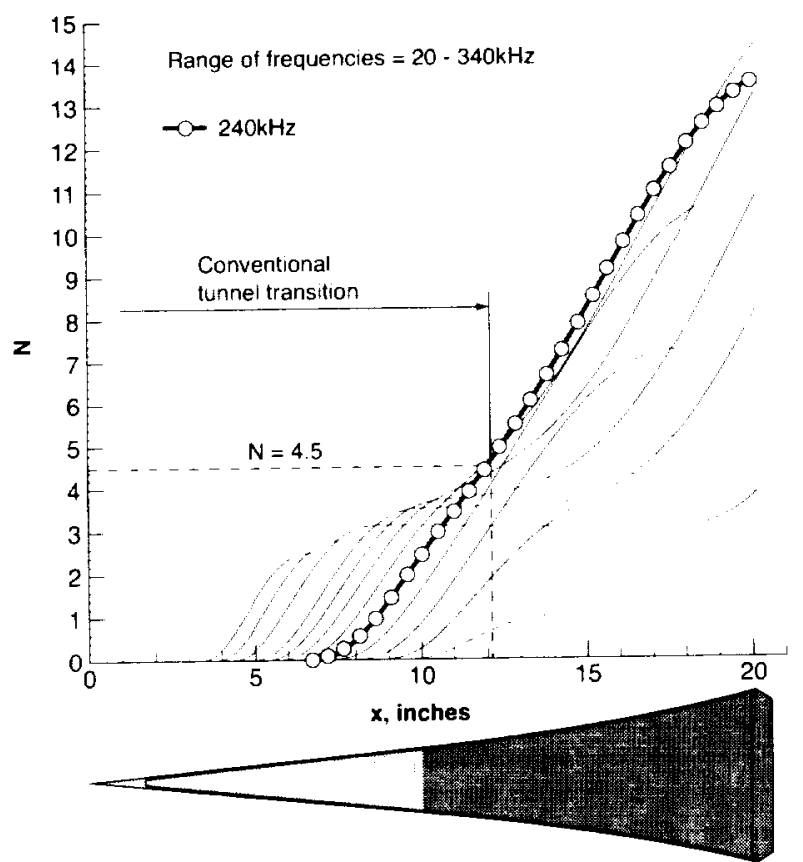

(a) Cold wall, $T_{w}=80.3 \mathrm{deg} F(300 \mathrm{~K})$

Instabilities associated with hypersonic boundary layers are quite sensitive to wall thermal conditions ${ }^{x ?}$. Stability calculations have indicated that wall-cooling destabilizes second-mode disturbances while stabilizing the first mode. Fig. 16a shows predicted flared cone second mode N factors obtained for a "cold" wall with a temperature of 80.3 degree $F(300 \mathrm{~K})$. As anticipated, the most amplified instability wave frequency increased to $240 \mathrm{kHz}$ for the cold wall case because the boundary layer has thinned. This frequency is close to the earlier stability predictions by Balakumar ${ }^{20}$ which indicated a slightly larger shift (up to $260 \mathrm{kHz}$ ). Compared to the adiabatic wall case, the $\mathrm{N}$ factors increased by approximately 1.5 for the most amplified waves. Assuming the correlated $N$ factor associated with second mode transition remained at 3.8 , the predicted change in the transition onset location under cold wall conditions would be at most a 0.5 -in. shift towards the nose. Experimentally, observations made on the sharp straight cone (see Fig. 6c) and on the sharp flared cone (not shown) indicated that the transition onset locations were indistinguishable for the adiabatic and transient coldwall cases at $\operatorname{Re}_{x}=2.8 \times 10^{6} / \mathrm{ft}$. As the thermocouple spatial resolution was 0.25 -in. the experimental results were not conclusive. The lack of movement in the transition onset location for adiabatic and cold wall conditions may also suggest that the linear amplification process is not as important in a conventional tunnel environment.

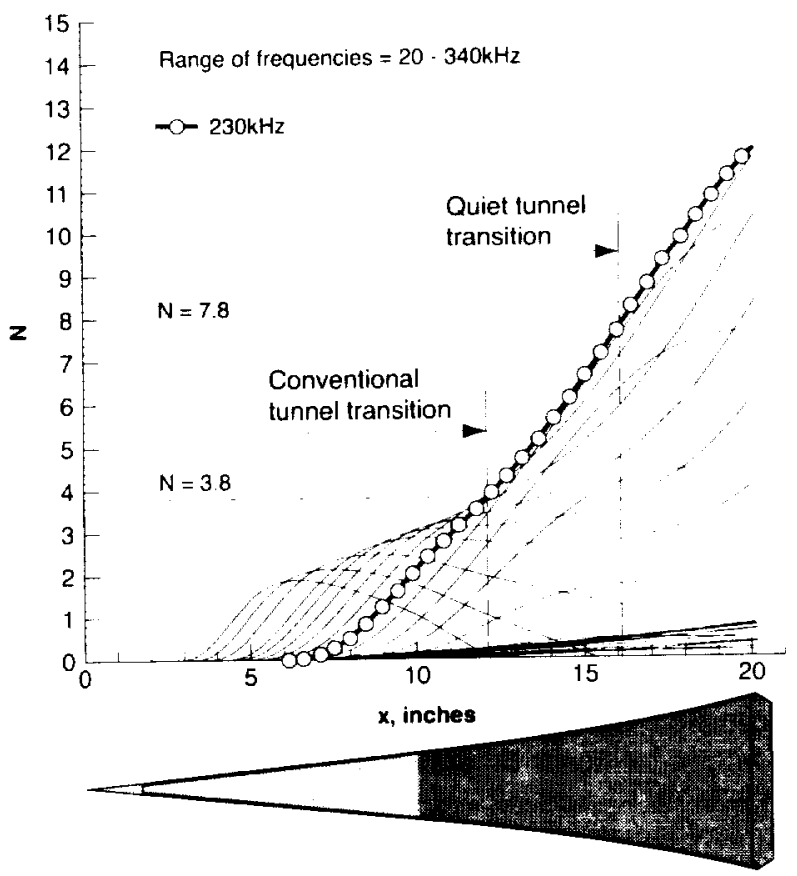

(b) Adiabatic wall condition

Fig.16. Flared cone second mode transition $N$-factor values for present Mach 6 transition onset location relative to that obtained in the NASA LaRC M=6 NTC Quiet Tunnel at a low disturbance level, $M_{\infty}=6, \quad R e_{\infty}=2.8 \quad x$ $10^{6} / \mathrm{ft}, \alpha=0$ deg, $R_{\mathrm{n}}=0.0001$ - in .

Table 2 summarizes the $\mathrm{N}$ values at transition onset for selected wind tunnel conditions. The table also includes second mode $\mathrm{N}$ factor values from linear PSE calculations. The PSE $\mathrm{N}$ factors are in general greater than the quasi-parallel LST $N$ values, which are used more often in transition correlations. Greater $N$ values in the linear PSE calculations may be attributed to non-parallel effects and the upstream shift of the neutrally stable location when PSE is employed. Similar effects have also been observed in earlier investigations $^{87.8 \%}$ for hypersonic flat-plate and cone boundary layers. The $N$ factors at transition onset for the present experimental measurements fall in a range of about 3 to 4.5 using linear stability theory and about 4 to 6.5 using linear PSE theory.

19 
14.Lachowicz J. T.. Chokani N., and Wilkinson S. P.. "Boundary-Latyer Stability Measurements in a Hypersonic Quiet Tunnel." AlAA Jommal. Vol. 34. No. 12. Dec.. 1996, pp 2496-2500.

15.Lachowicz J. T.. Chokani N., and Wilkinson S. P.. "Hypersonic Boundary Layer Stability over a Flared Cone in a Quict Tunnel," AIAA Paper 96-0782. Jan.. 1996.

16.Lachowicz J. T.. "Hypersonic Boundary-Layer Stability Experiments in a Quiet Wind Tunnel with Bluntness Effects," Ph.D. Dissertation. Mechanical and Aerospace Engineering Dept.. North Carolina State University, Raleigh, NC, November 1995.

17.Lachowicz. J. T. and Chokani N., "Hypersonic Boundary Laver Stability Experiments in a Quiet Wind Tunnel with Bluntness Effects. NASA CR-198272. January. 1996 .

18.Doggett, G. P., Chokani N.. and Wilkinson S. P. "Effect of Angel of Attack on Hypersonic BoundaryLatyer Stability," AIAA Journal, Vol. 35, No. 3. March. 1997. pp.464-470.

19.Doggett G. P., Chokani N.. and Wilkinson S. P. "Hypersonic Boundary-Layer Stability Experiments on a Flared-Cone Model at Angle of Attack in a Quiet Wind Tunnel," AlAA Paper 97-0557. January. 1997.

20.Doggett G. P., "Hypersonic Boundary-Layer Stability on a Flared-Cone Model at Angle of Attack." Ph.D. Dissertation, Mechanical and Acrospace Enginecring Dept., North Carolina State University, Raleigh. NC, May 1996.

21.Doggett G. P., and Chokani N., "Hypersonic BoundaryLayer Stability Experiments on a Flared-Cone Model at Angle of Attack in a Quiet Wind Tunnel," NASA CR 201617. October 1996 .

22.Blanchard A. E.. "An Investigation of Wall-Cooling Effects on Hypersonic Boundary-Layer Stability in a Quiet Wind Tunnel," Ph.D. Dissertation. Old Dominion University, Dept. of Mechanical Engineering. Norfolk. VA. December, 1995.

23.Blanchard, A .E.. and Selby. G. V., "An Experimental Investigation of Wall- Cooling Effects on Hypersonic Boundary-Layer Stability in a Quiet Wind Tunnel." NASA CR-198287. February. 1996.

24.Chokani, N., "Perspective: Stability Experiments at Hypersonic Speeds in a Quiet Wind tunnel," AIAA Paper 2001-0211. Jan.. 2001

25.Malik. M. R.. Balakumar, P., and Chang C.-L., "Effect of Adverse Pressure Gradient on the Second Mode Instability in Hypersonic Boundary Layers." High Technology Corporation., Report No. HTC-9006. Dec. 1990 .

26. Balakumar. P., and Malik M. R., "Effect of Adverse Pressure Gradient and Wall Cooling on Instability of Hypersonic Boundary Layers," High Technology Corporation., Report No. HTC-9404. March, 1994.
27.Schneider. S. P.. "Hypersonic Laminar Instability on Round cones Near Zero Angle of Attack." AIAA Paper 2001-0206, Jan.. 2001.

28.McDanicl, R. D.. and Hatssim, H. A.. "Role of Bypass Tramsition in conventional Hypersonic Facilities." AIAA Paper 2001-0209. Jan., 2001.

29. Mack L. M., "Linear Stability Theory and the Problem of Supersonic Boundary-Layer Transition." AlAA Journal, Vol. 13. No. 3, March. 1975. pp278-289.

30.Arnal. D.. "Boundary Layer Transition: Predictions Based on Linear Theory." AGARD R-793. April. 1994.

31.Maslov, et. al. "Hypersonic Flow Stability Experiments," AIAA Paper 2002-0153. Jan.. 2002.

32.Stetson. K. F.. and Kimmel, R. L.. "On Hypersonic Boundary-Layer Stability." AIAA Paper 92-0737. Jan. 1992.

33.Berry. S. A.. Bouslog. S. A., Brauckmann, G. J.. and Caram. J. M., "Shuttle Orbiter Experimental BoundaryLayer Transition Results with Isolated Roughness," Jounal of Spacecraft and Rockets. Vol. 35. No. 3. 1998. pp. $241-248$.

34.Berry. S. A., "Recent Shuttle Transition Results in the LaRC 20-Inch Mach 6 Tunnel," AIAA Paper 20022744. June, 2002.

35.Berry. S. A., Horvath. T. J., Hollis. B. R.. Thompson. R. A., and Hamilton, H. H., "X-33 Hypersonic Boundary Latyer Transition," deurnal of Spacecraft and Rockets, Vol. 38. No. 5. 2001. pp. 646-6.57.

36.Thompson. R. A.. Hamilton. H.H. II, Berry, S. A., and Horvath. T. J.. "Hypersonic Boundary Layer Transition for X-33 Phase II Vehicle." AIAA Paper 98-(1867. Jan.. 1998 .

37.Thompson, R. A., "Review of X-33 Hypersonic Acrodynamic and Acrothermodynamic Development." ICA 0323. August 2000.

38.Berry, S. A., Horvath. T. J.. DiFulvio. M.. Glass, C., and Merski, N. R., "X-34 Experimental Acroheating at Mach 6 and 10." Journal of Spacerraft and Rockets, Vol. 36, No. 2, 1998, pp. 171-178.

39.Horvath, T. J.. Berry, S. A.. Merski. N. R.. and Fitzgerald, S. M., "X-38 Experimental Aerothermodynamics," AIAA Paper 200()-2685. June, 2000 .

40.Berry. S. A., Horvath. T. J.. Roback, V. E., and Williams, G. B., "Results of Aerothermodynamic and Boundary Layer Transition Testing of 0.0362-Scalc X38 (Rev 3.1) Vehicle in NASA Langley 20)-Inch Mach 6 Tunnel." NASA TM 112857. Sept., 1997.

41.Berry. S. A.. Auslander, A. H.. Dilley. A. D., and Calleja, J. F., "Hypersonic Boundary-Layer Trip Development for Hyper-X," Journal of Spacecraft and Reckets. Vol. 38. No. 6. 2001.pp. 853-864.

42.Nance, R. P.. Hollis, B. R., Horvath, T. J., Alter. S. J.. and Hassan. H. A., "Computational Study of

American Institute of Aeronautics and Astronautics 
72.Baldwin, B. S. and Lomax, H.. "Thin Layer Approximation and Algebraic Model for Separated Turbulent Flow," AIAA Paper 78-257, Jan. 1978.

73.Cheatwood. F. M.. and Thompson. R. A.. "The Addition of Algebraic Turbulence Modeling to Program LAURA." NASA TM-107758. April 1993.

74.Dhawan. S.. and Narashima, R., "Some Properties of Boundary Layer Flow from Laminar to Turbulent Motion." Joumal of Flaid Mechanics. Vol. 1. Part 4. Jan. 1958, pp. 418-436.

75.Thomas, J.. Krist. S., and Anderson. W., "NavierStokes Computations of Vortical Flows Over Low Aspect-Ratio Wings." AIAA Joumal, Vol. 28.1990. pp. 205.

76.Krist, S.. Biedron, R. T.. and Rumsey. C. L. CFL3D User's Manual (version 5) Sept. 1997. (sec also http://fmad-www larc nasa.gov:80/ -biedron/ Cfl3dv6/cfl3dv6.html for Version 6 information).

77.Roc. P. "Approximate Riemann Solvers, Parameter Vectors, and Difference Schemes," I. Computational Phis. Vol. 43. PP. 357. 1981.

78. Chang, C.L.. "The Langley Stability and Transition Analysis Code (LASTRAC) - Part I LST. Linear and Nonlinear PSE for 2D, Axisymmetric and Infinite Swept Wing Boundary Layers, Proposed NASA TM. 2002 .

79. Malik, M. R.. and Spall. R. E.. "On the Stability of Compressible Flow past Axisymmetric Bodies." $I$. Fluid Mechanics, Vol. 228, pp. 443-463, 1991.

80.Pate. S. R.. "Dominance of Radiated Aerodynamic Noise on Boundary -Layer Transition in SupersonicHypersonic Wind Tunnels." AEDC-TR-77-107. March. 1978.

TABLE 1. Flow Conditions for the NASA LaRC 20-Inch Mach 6 Air Wind Tunnel.

\begin{tabular}{|c|c|c|c|}
\hline $\mathbf{R e}_{\infty} / \mathbf{f t}\left(\mathbf{\times 1 0} \mathbf{0}^{\circ}\right)$ & $\mathbf{M}_{\infty}$ & $\mathbf{P}_{0}(\mathbf{p s i a})$ & $\mathbf{T}_{0}\left({ }^{\circ} \mathbf{F}\right)$ \\
\hline 1.1 & 5.9 & 63 & 421 \\
\hline 2.2 & 5.9 & 124 & 450 \\
\hline 2.8 & 5.9 & 131 & 352 \\
\hline 2.8 & 5.9 & 156 & 445 \\
\hline 3.2 & 6.0 & 182 & 444 \\
\hline 4.3 & 6.0 & 257 & 445 \\
\hline 5.4 & 6.0 & 326 & 472 \\
\hline 6.2 & 6.0 & 372 & 470 \\
\hline 7.8 & 6.0 & 476 & 475 \\
\hline
\end{tabular}

Shaded conditions represent a match to Mach 6 NTC Quiet Tunnel reservoir conditions
81.Demetriades, A., "Comparison of Techniques for Defining the Transitional Region Extent." $5^{\text {th }}$ NASP Transition Workshop, NASA LaRC. Feb., 1992.

82.Zanchetta, M. A., and Hillier, R., "Blunt Cone Transition at Hypersonic Speeds: The Transition Reversal Regine," Proceedings of the colloquium on Transitional Bolundary Layers in Aeronautics. Amsterdam,Dec.. 1995, pp. 433-440.

83.Mack, L. M.. "Stability of Axisymmetric Boundary Latyers on Sharp Cones at Hypersonic Mach Numbers." AIAA Paper 87-1413, June 1987.

84. Malik, M R., "Prediction and control of Transition in Supersonic and Hypersonic Boundary Layers." AIAA Journal. Vol. 27. No. 11. Nov., 1989, pp. 1487-1493.

85.Bertin, J. J., Hyposonic Aerothermodynamics, edited by J. S. Przemieniecki,. AIAA Educational Series. AIAA, Washington, DC, 1994, pp. 373-395.

86. Schneider, S. P.. "Flight Data for Boundary-Layer Transition at Hypersonic and Supersonic Speeds," Joumal of Spaceraft and Rockets. Vol. 36. No. 1 . 1999, pp. 8-20.

87.Chang. C. -L.. "Non-Parallel Stability of compressible Boundary Layers." AIAA Paper 93-2912, 1993.

88. Stetson, K. F., Thompson, E. R., and Donaldson, J. C.. "Boundary-Layer Stability on a Cones at Mach 8," AIAA Paper 83-1761, 1983.

89.Chang. C. -L.. Malik. M R.. Erlebacher, G. and Hussaini, M. Y.." Compressible Stability of Growing Boundary Layers Using Parabolized Stability Equations." AlAA Paper 91-1636, 1991

TABLE 2. N-factor values correlated with measured transition onset on the flared cone.

\begin{tabular}{|c|c|c|c|}
\hline$R \mathbf{e}_{\infty} / \mathbf{f t}\left(\mathbf{x} \mathbf{1 0}^{\text {f }}\right)$ & $\mathbf{x}_{\mathbf{T}}$ (in.) & $\mathbf{N}$ (LST) & $\mathbf{N}$ (PSE) \\
\hline 2.2 & 14 & 3.0 & 4.0 \\
\hline 2.8 & 12.25 & 3.8 & 6.4 \\
\hline 2.8 (cold wall) & 12.25 & 4.5 & 6.3 \\
\hline 4.3 & 7.5 & 3.5 & 5.9 \\
\hline 6.2 & 6.0 & 4.0 & 6.5 \\
\hline
\end{tabular}


